\title{
Outsmarting a pulse oximeter: teaching spectrophotometry with a Foley catheter
}

\author{
Peter A. W. Collins, MD, FRCPC
}

Received: 11 June 2020/Revised: 16 June 2020/Accepted: 17 June 2020/Published online: 13 July 2020

(c) Canadian Anesthesiologists' Society 2020

To the Editor,

Pulse oximetry has become an essential monitor in the modern practice of anesthesiology. Since the first commercial pulse oximeter was patented in 1974, it has become a ubiquitous fixture in a variety of clinical environments. ${ }^{1}$ Nevertheless, an understanding of its use is paramount to recognizing its limitations and accurately interpreting its findings.

Spectrophotometry, the precursor to pulse oximetry, makes use of the Beer-Lambert law. Stated simply, the Beer-Lambert law describes the relationship between the concentration of a light-absorbing substance in solution and the amount of light transmitted through that solution. The more concentrated the substance is, or the greater distance the light travels through that substance (sample length), the more it will absorb light and the less light will be transmitted through that sample. To use blood as an example, oxyhemoglobin absorbs red light poorly compared with deoxyhemoglobin, which is why oxygenated blood appears a brighter red colour as more red light is reflected back to the observer's eye. In the infrared range, the situation is reversed as oxyhemoglobin absorbs infrared light much better than deoxyhemoglobin. Numerous technical issues with the simple application of the Beer-Lambert law in early devices led to the development of pulse oximetry.

To create a value for peripheral arterial oxygen saturation $\left(\mathrm{SpO}_{2}\right)$, the pulse oximeter compares the absorption of two different wavelengths of light (red light at $660 \mathrm{~nm}$ and infrared light at $940 \mathrm{~nm}$ ) taking advantage of

P. A. W. Collins, MD, FRCPC ( $\square)$

Faculty of Medicine, Discipline of Anesthesia, Memorial

University, St. John's, NL, Canada

e-mail: peterawcollins@gmail.com the different absorption patterns of oxyhemoglobin and deoxyhemoglobin at these points in the spectrum. To determine the saturation of only the pulsatile component of blood in a patient's finger, it has to subtract the nonpulsatile venous and capillary components. To do this, it analyzes the overall change in absorption of light over time and generates pulsatile (alternating current) and nonpulsatile (direct current) absorption readings, ultimately determining the final value of $\mathrm{SpO}_{2}$ using a ratio of these terms at both $660 \mathrm{~nm}$ and $940 \mathrm{~nm}$ and comparing this "ratio of ratios" to volunteer-derived data sets. ${ }^{2}$

As an interesting demonstration of its function for the purposes of education, one can generate a convincing pulse wave contour and value for $\mathrm{SpO}_{2}$ simply by utilizing a Foley catheter and a syringe filled with either saline or sterile water. Water absorbs visible light poorly and therefore appears transparent. It does, however, absorb small amounts of infrared light and can thus act as a blood surrogate in our "Foley finger". One only needs to manually apply intermittent pressure on the syringe to generate a trace similar to that presented in the Figure. The pulsatile signal seen is likely a product of the expanding and contracting balloon during intermittent manual syringe "pulsations" that transiently increases the lightwave pathlength resulting in more significant overall light absorption and therefore a significant pulsatile signal. The high value of $\mathrm{SpO}_{2}$ obtained could be a result of the fact that water, like oxyhemoglobin, absorbs red light poorly relative to infrared light.

\section{Disclosures None.}

\section{Funding statement None.}

Editorial responsibility This submission was handled by Dr. Hilary P. Grocott, Editor-in-Chief, Canadian Journal of Anesthesia. 
FIGURE The pulse oximeter reading and waveform created by manually applying an intermittent pressure on a saline-filled syringe into the balloon port of a Foley catheter. The high value of peripheral arterial saturation $\left(\mathrm{SpO}_{2}\right)$ could be because water, like oxyhemoglobin, absorbs red light poorly relative to infrared light.

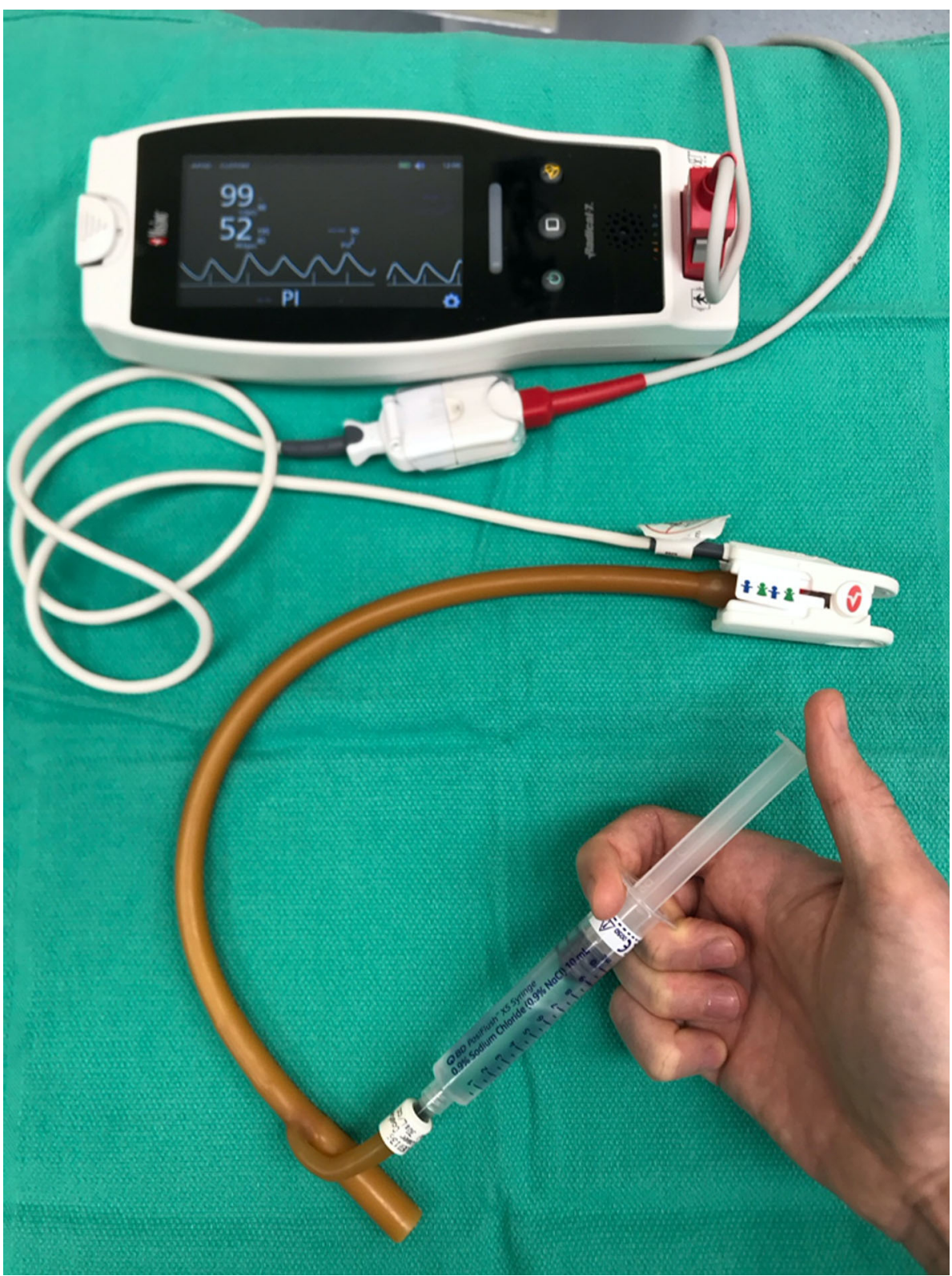

Publisher's Note Springer Nature remains neutral with regard to jurisdictional claims in published maps and institutional affiliations.

1. Van Meter A, Williams $U$, Zavala A, et al. Beat to beat: a measured look at the history of pulse oximetry. J Anesth Hist 2017; 3: 24-6.

2. Wukitsch MW, Petterson MT, Tobler DR, Pologe JA. Pulse oximetry: analysis of theory, technology, and practice. J Clin Monit 1988; 4: 290-301. 